\title{
A Primer on Macroprudential Policy
}

\author{
Jean-Christophe Poutineau* Gauthier Vermandel ${ }^{\dagger}$
}

October 14, 2014

\begin{abstract}
This paper introduces macroprudential policy using a static New Keynesian Macroeconomics model with financial frictions. We analyze two related questions: First, we show how the pro cyclicality of financial factors captured by the financial accelerator amplifies the transmission of supply and demand shocks and impacts the intuition we get from a basic intermediate macroeconomics. Second, adopting an optimal policy perspective, we show how a policymaker may use macroprudential policy to complete monetary policy measures. Following the Mundellian Policy Assignment principle, macroprudential policy should be specialized to address the pro cyclicality problem to suppress welfare losses associated with the building of financial imbalances, thus helping monetary policy to concentrate on the output inflation trade-off.
\end{abstract}

JEL codes: A20, E10, E50, F41.

Keywords: monetary policy, macroprudential policy, New Keynesian macroeconomics, financial frictions, optimal interest rate rules.

We thank the Editor and two anonymous referees for their constructive remarks on a first version of this paper. We are grateful to Thibaud Cargoet, Fabien Rondeau and Jean-Sebastien Pentecote for helpul discussions and comments on the initial version of this paper. We remain responsible for any errors and omissions.

${ }^{*}$ Corresponding author: jean-christophe.poutineau@univ-rennes1.fr, +33 2232333 58. CREM, UMR CNRS 6211, University of Rennes, Rennes, France.

${ }^{\dagger}$ CREM, UMR CNRS 6211, University of Rennes, Rennes, France. Email: gauthier@vermandel.fr. 


\section{A Primer on Macroprudential Policy}

\section{Introduction}

The financial turmoil of 2007 has significantly affected the landscape of short run macroeconomics. This episode has reassessed the amplifying role of financial factors in economic fluctuations. On the policy side, it has induced new practices in the conduct of monetary policy such as the adoption of unconventional measures. Furthermore, it has led economists to evaluate new policy practices regarding the way risks associated to financial decisions should be controlled to dampen output fluctuations. This episode has broken a general agreement limiting financial supervision at the micro level, while a new consensus has emerged, considering that prudential measures should also be set at the aggregate level through macroprudential measures.

As broadly defined by the International Monetary Fund, the final objective of macroprudential policy is to prevent or mitigate systemic risks that arise from developments within the financial system, taking into account macroeconomic developments, so as to avoid periods of widespread distress. The novel dimension introduced by macroprudential policy is to promote the stability of the financial system in a global sense, not just focusing on individual financial intermediaries. This aggregate approach aims at solving a fallacy of composition in the evaluation of financial distress. A simple example makes this fallacy easy to understand: it is rational for a bank to sell assets with a decreasing value to mitigate the risk at the individual level. However, generalizing this decision at the aggregate level is not optimal for the economy as a whole since it leads to a higher decrease in the price of this asset thus amplifying financial troubles. The definition of macroprudential measures is thus necessary to avoid this kind of problem.

Macroprudential policy should now be treated as a specific topic in intermediate macroeconomics courses, as the implementation of such measures is becoming a generalized practice of developed economies to prevent the building of financial imbalances. However, the litera- 
ture available on this subject is generally not well suited to this teaching objective. Most of the published papers are either institutional (describing how such practices should be introduced in existing institutional set up) or devoted to theoretical aspects generally based on Dynamic Stochastic General Equilibrium (DSGE) modelling (for a survey, see for example Galati \& Moessner, 2013).

The aim of this paper is to convey the basic ideas of what macroprudential policy is. Its objective is to bridge the gap between recent theoretical progress made by DSGE models regarding the way macroprudential measures should be conducted and a more standard model used to teach short run macroeconomics as encountered in undergraduate textbooks. We provide a simple and compact presentation of the main elements that could be introduced in an intermediate macroeconomics course to account for the impact of financial factors on the determination of macroeconomic equilibrium and for the development of policy measures designed to dampen the consequences of financial imbalances.

This paper develops a closed economy static framework in line with some recent papers recently published to present the new developments of monetary policy practices to intermediate level students ${ }^{1}$. In this paper we use a static version of the "3-equations New Keynesian Macroeconomics" model such as the one introduced by Bofinger et al. (2006) extended to account for financial frictions and macroprudential policy. It analyses two related questions: First it shows how incorporating financial frictions impacts the intuition we get from a basic undergraduate intermediate macroeconomic model. Second, it shows how a policymaker who is concerned about financial stability would use macroprudential policy tools, as a complement to monetary policy measures, to stabilize the economy.

The rest of the paper is organized as follows. Section II introduces the model and evaluates how financial frictions amplify the transmission of demand and supply shocks on the macroeconomic equilibrium. Section III discusses the interest of combining macroprudential and monetary policy measures to stabilize the economy. Section IV concludes. 


\section{The Effect of Financial Frictions in the Case of a Simple Monetary Policy Rule}

This first section extends a static version of the three-equations New Keynesian macroeco-

nomics model to take into account the role of the banking system on the determination of the macroeconomic equilibrium. We complete existing models such as Bofinger et al. (2006) with a fourth equation that describes the financial accelerator related to lending conditions.

To underline the key role of lending decisions in shaping output developments, it is useful to provide students with a simple representation such as Figure 1.

[Insert Figure 1 about here]

As observed, the financial developments of credit in the US economy move in line with activity. In particular during the recent financial crisis, it is easy to see how the credit crunch is in line with contraction of US output. The first step of the discussion presented to students should thus be to understand the procyclicality of financial decisions and the consequences of this phenomenon in the transmission of demand and supply shocks.

\section{A Static New Keynesian Model with a Banking System}

We build a static new Keynesian model that accounts for a banking system. The benchmark model - namely, a Phillips curve (PC), an IS curve and a Monetary Policy (MP) rule - is affected by financial frictions and a fourth equation describes the Financial Accelerator (FA),

$$
\begin{aligned}
& P C: \pi=\pi_{0}+\sigma_{y} y+\epsilon_{S}, \\
& I S: y=-\alpha_{r}\left(r-r_{n}\right)-\alpha_{\rho} \rho+\epsilon_{D}, \\
& M P: r=r_{n}+\beta_{y} y+\beta_{\pi}\left(\pi-\pi_{0}\right) . \\
& F A: \rho=r-\theta_{y} y .
\end{aligned}
$$

The Phillips curve and the monetary policy rule are standard. In the new Keynesian 
Phillips Curve (PC) $\pi$ is the rate of inflation, $y$ is the output gap and $\epsilon_{S}$ is a cost-push shock on the supply side (a positive realization of this shock describes an exogenous increase in goods prices). We assume that monetary policy is credible (so that, inflation expectations are based on the targeted inflation rate, $\pi_{0}$, as in Bofinger et al. (2006)). Parameter $\sigma_{y}$ is the elasticity of inflation to the output gap. Regarding monetary policy $(M P)$, authorities control the policy relevant interest rate, $r$, according to a Taylor rule. Here, $\beta_{y}$ is the elasticity of the interest rate to the output gap and $\beta_{\pi} \geq 1$ is the elasticity of the interest rate to the inflation rate.

The $I S$ curve is affected by financial frictions. We account for the fact that some agents (such as big firms) can issue bonds to finance their investment, while others (small firms or households) are credit constrained and must borrow from the banking system (Woodford (2010)). The simplest solution for the possibility of banks having an impact on the level of activity (though the fraction of aggregate investment projects financed with loans) is to follow Bernanke \& Blinder (1989) and to distinguish two interest rates in the $I S$ curve. The lending rate $(\rho)$ is determined by the equilibrium in the lending market while the short run interest rate on bonds $(r)$ is set by the monetary authority (Cecchetti \& Li (2008), Cecchetti \& Kohler (2012)). Thus agents that borrow from banks to finance their investment are faced with an interest rate that differs from the interest rate set by monetary authorities. Finally, $r_{n}$ is natural interest rate (so that in the absence of shocks and financial frictions the output gap is zero and $\left.r=r_{n}\right), \epsilon_{D}$ is a demand shock, $-\alpha_{r}$ is the elasticity of the output gap to the policy oriented interest rate, and $-\alpha_{\rho}$ is the elasticity of the output gap to the interest rate on bank loans. We go back to the standard IS curve if $\alpha_{\rho}=0$.

The last equation of the model $(F A)$ explains the determination of the interest rate for private sector loans ${ }^{2}$. As underlined by Woodford (2010) in actual economies, the different interest rates do not co-move perfectly. This relation provides a simple channel to account for the procyclicality of financial factors. According to this relation, the external finance premium $(\rho-r)$ is countercyclical as a positive output gap reduces the interest rate spread. 
The financial accelerator operates as follows: as a positive output gap increases income in the economy loans are more likely to be repaid, leading to a reduction in the risk premium. By relaxing the interest rate spread, it leads to more investment, that in turn implies a further increase in the output gap.

To get a clear understanding of the realization of the macroeconomic equilibrium, we focus on three main "gaps": the output gap y (i.e., the difference between actual and full employment output), the inflation gap $\pi-\pi_{0}$ (i.e., the difference between the actual and the targeted inflation rate) and the interest rate spread $\rho-r$ (i.e., the difference between the interest rate on bank loans and the interest rate of the central bank). All along the paper we evaluate the consequences of the different policy settings on these three main indicators.

\section{The Consequences of the Procyclicality of the Financial System}

The model (1)-(4) can be solved sequentially to evaluate the effect of financial frictions on key relations such as the $I S$ and $A D$ curves. First, combining the $I S$ and $F A$ relations, we get the financially constrained $I S-F A$ relation,

$$
I S-F A: y=\frac{\alpha_{r} r_{n}}{\left(1-\alpha_{\rho} \theta_{y}\right)}-\frac{\left(\alpha_{r}+\alpha_{\rho}\right)}{\left(1-\alpha_{\rho} \theta_{y}\right)} r+\frac{1}{\left(1-\alpha_{\rho} \theta_{y}\right)} \epsilon_{D}
$$

The standard expression of the $I S$ schedule is obtained when disabling credit frictions (i.e. imposing $\alpha_{\rho}=0$ in the previous expression). Financial frictions affect both the slope of the $I S$ curve and the impact of demand shocks on the situation of this schedule in the $(y, r)$ space. Second, combining the constrained $I S-F A$ curve (2) with the Taylor rule (3), we get the Aggregate Demand schedule that accounts for the Banking system $(A D B)$ as,

$$
A D B: y=\frac{\alpha_{r} r_{n}-\left(\alpha_{r}+\alpha_{\rho}\right)\left[r_{n}+\beta_{\pi}\left(\pi-\pi_{0}\right)\right]+\epsilon_{D}}{\left(1-\alpha_{\rho} \theta_{y}\right)+\left(\alpha_{r}+\alpha_{\rho}\right) \beta_{y}}
$$

The standard expression of the Aggregate Demand $(A D)$ schedule is obtained without financial frictions (i.e. imposing $\alpha_{\rho}=0$ in the previous expression). The equilibrium of the 
model that solves the $A D B-P C$ system is,

$$
\begin{aligned}
y & =\frac{\alpha_{r} r_{n}-\left(\alpha_{r}+\alpha_{\rho}\right)\left[r_{n}+\beta_{\pi} \epsilon_{S}\right]+\epsilon_{D}}{\left(1-\alpha_{\rho} \theta_{y}\right)+\left(\alpha_{r}+\alpha_{\rho}\right)\left(\beta_{y}+\beta_{\pi} \sigma_{y}\right)} \\
\pi-\pi_{0} & =\frac{\sigma_{y}\left(\alpha_{r} r_{n}+\epsilon_{D}-\left(\alpha_{r}+\alpha_{\rho}\right) r_{n}\right)+\left[\left(1-\alpha_{\rho} \theta_{y}\right)+\left(\alpha_{r}+\alpha_{\rho}\right) \beta_{y}\right] \epsilon_{S}}{\left(1-\alpha_{\rho} \theta_{y}\right)+\left(\alpha_{r}+\alpha_{\rho}\right)\left(\beta_{y}+\beta_{\pi} \sigma_{y}\right)} \\
\rho-r & =\frac{\theta_{y}\left(\alpha_{r}+\alpha_{\rho}\right)\left[r_{n}+\beta_{\pi} \epsilon_{S}\right]-\theta_{y}\left(\epsilon_{D}+\alpha_{r} r_{n}\right)}{\left(1-\alpha_{\rho} \theta_{y}\right)+\left(\alpha_{r}+\alpha_{\rho}\right)\left(\beta_{y}+\beta_{\pi} \sigma_{y}\right)}
\end{aligned}
$$

The consequences of financial frictions on the diffusion of supply $\left(\epsilon_{S}\right)$ and demand $\left(\epsilon_{D}\right)$ shocks are reported in Table 1. As observed, in the case of procyclicality of financial factors (namely when $\theta_{y}>0$ ), supply and demand shocks amplify the variation of the output gap. In contrast, the inflationary consequences of the supply shocks are dampened with financial frictions.

[Insert Table 1 about here]

To understand the results of Table 1, we illustrate graphically these two shocks in Figure $2 \mathrm{a}$ and Figure $2 \mathrm{~b}$. The standard model is depicted in the $(y, \pi)$ space by the $A D-P C$ schedules, while the model with the banking system is depicted by the $A D B-P C$ schedules. With $\theta_{y}>0$, the slope of the $A D B$ curve is flatter than the standard $A D$ curve (where, $\left.\theta_{y}=0\right)$.

\section{[Insert Figure 2 about here]}

In figure $2 \mathrm{a}$, a positive cost push shock $\left(\epsilon_{S}>0\right)$ moves the $P C$ schedule upwards. As a negative supply shock, it leads to a negative output gap and an increase in inflation. The procyclicality of financial factors amplifies the negative impact of the shock as this tends to increase the interest rate gap in the economy and, as a by-product, implies a higher decrease in the output gap as $\left(y_{C}<y_{B}\right)$. In the meanwhile, as the procyclicality of financial factors reduces more aggregate demand in the economy, the cost-push shock leads to less inflation $\left(\pi_{B}>\pi_{C}\right)$ 
In figure $2 \mathrm{~b}$, a positive demand shock $\left(\epsilon_{D}>0\right)$ moves the $A D B$ schedule rightward further than the baseline $A D$ curve, as $\theta_{y}>0$. For an unchanged $P C$ schedule, this amplifies both the output and the inflation gaps. Indeed, the procyclicality of financial factors amplifies the positive impact of the shock as this tends to decrease the interest rate gap in the economy: by improving the solvability of borrowers, a higher output gap leads banks to decrease the interest rates on private loans. This implies a further increase in the output gap $\left(y_{C}>y_{B}\right)$, which in turn has a higher impact on the inflation rate $\left(\pi_{C}>\pi_{B}\right)$.

As illustrated by this simple model, the procyclicality of the financial sector leads to higher fluctuations in the output gap and, by so, may require a specific reaction of the authorities over the standard policy of targeting inflation.

\section{Optimal Policy and the Concern for Financial Stability}

As the procyclicality of financial decisions amplifies the impact of shocks on the output gap, the natural question that arises is to determine how authorities should react to the building of financial imbalances. This problem is traditionally analyzed in the context of the choice of an optimal monetary policy. As a main interest, this approach (discussed by Bofinger et al. (2006) in a static framework) computes the interest rate reaction to supply and demand shocks on the basis of the minimization of the country loss function. The sensitivity of the interest rate reaction to shocks is thus determined endogenously, depending on the objective(s) of the policy.

In this section we outline economic factors that favor the use of macroprudential policy as a complement to standard monetary policy measures. We successively consider three possible arrangements: (i) a standard monetary policy setting, where authorities care only about the output gap and price stability, (ii) an extended monetary policy that accounts for financial concerns and (iii) the implementation of macroprudential measures, coordinated with a standard monetary policy. 


\section{Optimal Monetary Policy without a Financial Stability Concern}

In the standard analysis of optimal monetary policy, the interest rate is chosen by the authorities to minimize a quadratic loss function $(\mathbf{L})$ expressed in terms of the output gap, $y$, and the inflation gap $\left(\pi-\pi_{0}\right)$,

$$
\mathbf{L}=\frac{1}{2} y^{2}+\frac{\gamma_{1}}{2}\left(\pi-\pi_{0}\right)^{2}
$$

subject to the supply constraint $P C$ (equation (1)) of the private sector. In this expression, $\gamma_{1}$ represents the weight imposed on inflation rate deviations with respect to the full employment target. The first order conditions that solve this problem can be combined to get the targeting rule as,

$$
y^{o p t}=-\sigma_{y} \gamma_{1}\left(\pi^{o p t}-\pi_{0}\right) .
$$

This targeting rule defines the desired balance that the central bank wants to reach between full employment and price stabilization. It accounts for both society's inflation reluctance $\left(\gamma_{1}\right)$ and the elasticity of the inflation rate to the output gap in the Phillips curve $\left(\sigma_{y}\right)$. The marginal rate of substitution between inflation and the output gap (a sort of "sacrifice ratio") is determined by,

$$
\frac{\partial\left(\pi^{o p t}-\pi_{0}\right)}{-\partial y^{o p t}}=\frac{1}{\sigma_{y} \gamma_{1}},
$$

so the central bank accepts a higher increase in inflation $\left(\partial\left(\pi^{\text {opt }}-\pi_{0}\right)\right)$ following a $1 \%$ reduction in the output gap $\left(-\partial y^{o p t}\right)$ when the weight associated to the objective of price stability is lower $\left(\gamma_{1}\right)$ or for a lower elasticity of the inflation rate with respect to the output gap $\left(\sigma_{y}\right)$. The solution of the optimal monetary policy ${ }^{3}$ is summarized in Table 2. As observed, we get a new version of the "divine coincidence" that also applies to the interest rate differential ${ }^{4}$. Namely, acting optimally (i.e., setting the best value for the interest rate), the monetary authorities are able to close the output gap following a demand shock. Acting so, they reach the inflation target and there is no effect of the demand shock on the output 
and interest rate gaps. To support this equilibrium monetary authorities must set their interest rate as,

$$
r^{o p t}=\frac{\alpha_{r} r_{n}}{\left(\alpha_{r}+\alpha_{\rho}\right)}+\frac{\left(1-\alpha_{\rho} \theta_{y}\right) \gamma_{1} \sigma_{y}}{\left(\alpha_{r}+\alpha_{\rho}\right)\left(1+\gamma_{1} \sigma_{y}\right)} \epsilon_{S}+\frac{1}{\left(\alpha_{r}+\alpha_{\rho}\right)} \epsilon_{D}
$$

\section{Optimal Monetary Policy with a Financial Stability Concern}

Monetary authorities may also adjust the short term interest rate in an effort to reduce the building of financial imbalances. In this case, the authorities' loss function $\left(\mathbf{L}^{\prime}\right)$ should be extended to account for the spread between the lending and the policy oriented interest rates, as proposed by Cecchetti \& Kohler (2012),

$$
\mathbf{L}^{\prime}=\frac{1}{2} y^{2}+\frac{\gamma_{1}}{2}\left(\pi-\pi_{0}\right)^{2}+\frac{\gamma_{2}}{2}(\rho-r)^{2}
$$

In this expression, the relative weight regarding the inflation gap $\left(\gamma_{1}\right)$ and the interest rate spread $\left(\gamma_{2}\right)$ are expressed with respect to the full employment target. As the authorities are now making an arbitrage between three main concerns, they minimize this function subject to the Phillips curve $P C$ (equation (1)) and the financial accelerator $F A$ (equation (4)). Combining the three first order conditions that solve this minimization program, we now get a targeting rule that combines the three policy concerns as,

$$
y^{o p t}=\gamma_{1} \sigma_{y}\left(\pi^{o p t}-\pi_{0}\right)+\gamma_{2} \theta_{y}\left(\rho^{o p t}-r^{o p t}\right) .
$$

Combining this expression with the Financial accelerator $(F A)$, the marginal rate of substitution between inflation and the output gap is now given as,

$$
\frac{\partial\left(\pi^{o p t}-\pi_{0}\right)}{-\partial y^{o p t}}=\frac{1+\theta_{y}^{2} \gamma_{2}}{\sigma_{y} \gamma_{1}}>\frac{1}{\sigma_{y} \gamma_{1}}
$$


If the central bank interest rate decision accounts for financial stability as well as price stability, it should accept a higher increase in inflation following a $1 \%$ reduction in the output gap. Combining the targeting rule, the Phillips curve and the financial accelerator relation, we get the reduced form of the results as reported in the second column of Table 2.

[Insert Table 2 about here]

Finally, using the $I S$ curve to compute the interest rate needed to support this equilibrium, we get,

$$
r^{o p t}=\frac{\alpha_{r} r_{n}}{\left(\alpha_{r}+\alpha_{\rho}\right)}+\frac{\left(1-\alpha_{\rho} \theta_{y}\right) \gamma_{1} \sigma_{y}}{\left(\alpha_{r}+\alpha_{\rho}\right)\left(1+\gamma_{1} \sigma_{y}^{2}+\gamma_{2} \theta_{y}^{2}\right)} \epsilon_{S}+\frac{1}{\left(\alpha_{r}+\alpha_{\rho}\right)} \epsilon_{D}
$$

The divine coincidence is still observed at the general equilibrium of the model: the authorities are able to close the output gap, the inflation and the interest rate spread following a demand shock. However, the picture is a bit different regarding the impact of a cost push shock. As observed, the introduction of financial stability concerns in the definition of an optimal monetary policy affects the macroeconomic outcome, as it clearly stabilizes both the output and interest rate gaps, while it deteriorates price stability. Indeed, contrasting the authorities' interest rate reaction in the two situations, we find that extending the mandate of monetary policy to stabilize the interest rate spread leads to a smaller increase in the interest rate in case of supply shocks. As monetary policy is less restrictive, inflation is higher while the interest rate spread is lower.

Targeting financial stability as a supplementary objective of monetary policy defined in terms of an optimal interest rate rule deteriorates price stability. This result illustrates the problem of a missing instrument to achieve a supplementary goal. As already underlined by Tinbergen (1952), one further (linearly independent) policy target requires one further (linearly independent) instrument. Thus, macroprudential policy can be introduced as a simple solution to this missing instrument problem. 


\section{Macroprudential Policy}

The management of financial stability as an supplementary concern of monetary policy is a debated question. By so, the introduction of an additional macroeconomic policy instrument aimed at mitigating financial imbalances appears as a natural solution to solve the Tinbergen problem outlined in the previous subsection.

We introduce macroprudential concerns using bank capital requirements as an instrument ${ }^{5}$ and analyze how such measures should be taken in conjunction with monetary policy decisions. We follow Cecchetti \& Kohler (2012), by assuming that the instrument set by the relevant authorities is related to bank capital requirements $(k)$. Now, the value of the lending rate $\rho$ is determined according to,

$$
F A^{\prime}: \rho-r=-\theta_{y} y+\theta_{k} k
$$

where $\theta_{k}$ is the elasticity of the interest rate gap to the bank capital requirement. This relation provides a simple channel to account for the procyclicality of financial factors and the possibility to conduct preventive macroprudential measures. In this situation, the authorities in charge of financial stability can control the interest rate spread with their own policy

instrument, $k$. As a consequence, the interest rate $r$ can be used conventionally by the central bank to stabilize prices in the economy. As an example, if the banking system issues too much loans with respect to the macroeconomic performance of the economy, a rise in the value of $k$, by increasing the interest rate paid on loans, may reduce the incentives to borrow. It thus reduces the incentive for risk taking and builds up buffers ex-ante to avoid a financial crisis.

Following De Paoli \& Paustian (2013), both the monetary and macroprudential authorities care about the output gap because it is affected by nominal rigidities and credit frictions. However, the monetary authority cares about the social welfare function except for the credit spread term, because the latter is taken care of by the macroprudential authority. 
As a consequence the monetary authority loss function is still defined by $\mathbf{L}$. In contrast, the macroprudential authority cares about social welfare except for the inflation term, which it is taken care of by the monetary authority. Thus, following De Paoli \& Paustian (2013), the macroprudential authority minimizes a loss function (M) combining the output gap ${ }^{6}$ and the interest rate gap,

$$
\mathbf{M}=\frac{1}{2} y^{2}+\frac{\gamma_{2}}{2}(\rho-r)^{2}
$$

In this expression, the relative weight regarding the interest rate spread $\left(\gamma_{2}\right)$ is expressed with respect to the full employment target.

The two policy instruments (namely $r$ and $k$ ) cannot be set independently. First, concentrating on the $F A^{\prime}$ relation, ceteris paribus (for a given output gap), an increase in the interest rate $r$ leads to a reduction of the interest rate spread which may affect the value of $k$ set by the macroprudential authorities. Second, the bank capital requirement $k$ affects the interest rate spread, and thereby the output gap, which in turn affects the interest rate $r$. To avoid potential conflicts between the two policies, we assume that the policy interest rate and the bank capital requirement are determined jointly by a common policy agency (i.e., we compute the cooperative equilibrium of the model). We assume that both authorities are treated equally by the common agency, that minimizes a loss function $\mathbf{N}$ defined as the average of the two other authorities (i.e., $\mathbf{N}=\frac{1}{2}(\mathbf{L}+\mathbf{M})$ ). Formally, this agency aims at minimizing,

$$
\mathbf{N}=\frac{1}{2} y^{2}+\frac{\gamma_{1}}{4}\left(\pi-\pi_{0}\right)^{2}+\frac{\gamma_{2}}{4}(\rho-r)^{2}
$$

subject to the Phillips curve $P C$ (equation (1)) and the financial accelerator $F A^{\prime}$ (equation (8)). The targeting rule of the joint authority is now defined as,

$$
y=-\sigma_{y} \frac{\gamma_{1}}{2}\left(\pi-\pi_{0}\right)+\theta_{y} \frac{\gamma_{2}}{2}(\rho-r)
$$

The equilibrium solution of the model is obtained by finding five variables with only four equations. The only possibility to get a solution in this situation is to proceed sequentially as 
follows: the cooperative situation allows the joint authority to close the interest rate spread $(\rho-r=0$ in equation (8)), so that the macroprudential instrument should be set according to,

$$
k=\frac{\theta_{y}}{\theta_{k}} y
$$

This result illustrates the Mundellian Policy Assignment principle: in the cooperative equilibrium, capital requirements should be specialized to address the procyclicality problem. This instrument must be set (proportionally to the elasticity $\theta_{y}$ ) with respect to the fluctuations in the output gap. In this case, the targeting rule of the authorities degenerates to,

$$
y^{o p t}=-\frac{\sigma_{y} \gamma_{1}}{2}\left(\pi^{o p t}-\pi_{0}\right),
$$

so, that with macroprudential policy, the marginal rate of substitution between inflation and the output is,

$$
\frac{\partial\left(\pi^{o p t}-\pi_{0}\right)}{-\partial y^{o p t}}=\frac{2}{\sigma_{y} \gamma_{1}} .
$$

even if this value is higher to the original monetary policy solution, it may lead to better results than the extended monetary policy on inflation if $\theta_{y}^{2} \gamma_{2}>1$. This condition is met for a high procyclicality of financial decisions $\left(\theta_{y}\right)$ and a high reluctance of the society with respect to financial stress $\left(\gamma_{2}\right)$. The reduced form of the macroeconomic equilibrium reached with macroprudential policy is reported in the third column of Table 2. This equilibrium requires the policy stance to be defined as follows,

$$
\begin{aligned}
k^{o p t} & =-\frac{\theta_{y}}{\theta_{k}} \frac{\sigma_{y} \gamma_{1}}{\left(2+\sigma_{y}^{2} \gamma_{1}\right)} \epsilon_{S}, \\
r^{o p t} & =\frac{\alpha_{r} r_{n}}{\left(\alpha_{r}+\alpha_{\rho}\right)}+\frac{1}{\left(\alpha_{r}+\alpha_{\rho}\right)} \epsilon_{D}+\frac{\left(1-\alpha_{\rho} \theta_{y}\right)}{\left(\alpha_{r}+\alpha_{\rho}\right)} \frac{\sigma_{y} \gamma_{1}}{\left(2+\sigma_{y}^{2} \gamma_{1}\right)} \epsilon_{S} .
\end{aligned}
$$

As reported in Table 2 the distribution of "gaps" in the economy is affected by the choice between an extended monetary policy accounting for financial stress and the introduction of macroprudential decisions. More particularly, the combination of a standard monetary 
policy with a macroprudential policy leads to better results in terms of inflation and interest gaps than the extended monetary policy situation. Thus, introducing a macroprudential instrument in the conduct of macroeconomic policy may restore more efficiency regarding price stability with a very good results on financial imbalances. However, as monetary policy is more reactive to inflation developments, it has a relatively more negative impact on activity.

The interest of the macroprudential solution may be assessed by contrasting the welfare loss in the economy. Consolidating the reduced form of the three "gaps" and the loss functions, we get,

$$
\mathbf{L}^{\prime}=\frac{1}{2}\left(\frac{-\sigma_{y} \gamma_{1}}{1+\theta_{y}^{2} \gamma_{2}+\sigma_{y}^{2} \gamma_{1}} \epsilon_{S}\right)^{2}+\frac{\gamma_{1}}{2}\left(\frac{1+\theta_{y}^{2} \gamma_{2}}{1+\theta_{y}^{2} \gamma_{2}+\sigma_{y}^{2} \gamma_{1}} \epsilon_{S}\right)^{2}+\frac{\gamma_{2}}{2}\left(\frac{\sigma_{y} \theta_{y}^{2} \gamma_{2}}{1+\theta_{y}^{2} \gamma_{2}+\sigma_{y}^{2} \gamma_{1}} \epsilon_{S}\right)^{2}
$$

for the extended monetary policy, and,

$$
\mathbf{N}=\frac{1}{2}\left(-\frac{\sigma_{y} \gamma_{1}}{2+\sigma_{y}^{2} \gamma_{1}} \epsilon_{S}\right)^{2}+\frac{\gamma_{1}}{4}\left(\frac{2}{2+\sigma_{y}^{2} \gamma_{1}} \epsilon_{S}\right)^{2}
$$

for the implementation of macroprudential measures with a standard monetary rule. As observed, the final ranking between the two institutional arrangements partly depends on the procyclicality of financial decisions, as a higher value of $\theta_{y}$ by increasing $\mathbf{L}^{\prime}$ with respect to $\mathbf{N}$ makes the implementation of macroprudential measures more interesting to dampen financial imbalances. Following the Mundellian Policy Assignment principle, macroprudential policy focuses on the procyclicality problem. Remarkably, the optimality of the cooperative solution also increases with the society reluctance parameters regarding both price $\left(\gamma_{1}\right)$ and financial $\left(\gamma_{2}\right)$ instability. As previously shown, using macroprudential policy to close the interest rate spread leads to better results in terms of price stability. Accordingly, it suppresses welfare losses associated with the building of financial imbalances. Thus, the gap distribution reached with macroprudential policy leads to a higher welfare in the economy. 


\section{Conclusion}

The implementation of macroprudential measures is becoming a generalized practice in developed economies to prevent the building of financial imbalances such as the ones that led to the crisis of 2007-2009. The aim of this paper was to convey the interest of this policy, using a simple static new Keynesian model extended to account for financial frictions. We analyzed the destabilizing nature of financial frictions in the transmission of real shocks and we discussed how a policymaker who is concerned about financial stability would use macroprudential policy tools as a complement to monetary policy measures. We show that combining a standard monetary policy with macroprudential measures should be preferred to an extended monetary policy when financial decisions are highly procyclical and/or a the society is highly reluctant to financial stress and inflation.

The analysis provided in this paper can be extended in various directions for higher level students. To name just a few possibilities, it is easy to relax the assumption of a unitary interest rate pass through, to evaluate the nature of the macroprudential policy when the divine coincidence does not hold. A second interesting possibility should be to analyze the optimal macroprudential policy in an open economy to evaluate the gain that can obtained by coordinating national decisions in a world of perfect capital mobility.

\section{A Appendix : the Banking Sector and the Financial Accelerator}

This appendix is devoted to the derivation of the financial accelerator (as reported in the text in relations $F A$ and $F A \prime)$ using a simple description of the banking sector.

First, following Cecchetti \& Li (2008), the amount of loans supplied by the banking

system $\left(L^{S}\right)$ depends on bank capital $(B)$ and on the net amount of deposits $(D)$ over the 
amount needed in terms of reserves,

$$
\begin{aligned}
& L^{S}=B+\tau D \\
& B=b y \\
& D=\delta_{y} y-\delta_{r} r
\end{aligned}
$$

where, $\tau$ is equal to one minus the rate of bank reserves. We assume that bank capital positively reacts to the output gap, where $b$ is the sensitivity of bank capital to the output gap. As underlined by Woodford (2010), an increase in activity boosts the value of the banks' assets as loans are more likely to be repaid. This, in turn, allows a larger volume of credit distribution for any given interest rate spread. Following Cecchetti \& Kohler (2012), deposits are positively related to the output gap (with sensitivity $\delta_{y}$ ) and negatively to the policy rate (with sensitivity $-\delta_{r}$ ). Second, the level of loan demand from households and firms $\left(L^{D}\right)$ is positively related to the output gap (with sensitivity $l_{y}$ ) and is negatively related to the lending rate (with sensitivity $-l_{\rho}$ ),

$$
L^{D}=l_{y} y-l_{\rho} \rho
$$

After imposing the credit market clearing condition $\left(L^{S}=L^{D}\right)$, the value of the lending rate $\rho$ that solves this equilibrium condition writes,

$$
\rho=-\theta_{y} y+\theta_{r} r
$$

This relation introduces two financial channels that affect the way supply and demand shocks are transmitted to the macroeconomic equilibrium. The first parameter $\theta_{y}=\left[\left(b+\tau \delta_{y}\right)-l_{y}\right] / l_{\rho}$ measures the elasticity of the interest rate to output gap, while the second parameter $\theta_{r}=\tau \delta_{r} / l_{\rho}$ accounts for the imperfect interest rate pass-through. These two parameters summarize how the banking system affect the macroeconomic equilibrium, through the diffu- 
sion of supply and demand shocks and through the transmission of monetary policy decisions to the rest of the economy.

The first elasticity $\theta_{y}$ accounts for the procyclicality of the financial system if $\left(b+\tau \delta_{y}\right)>$ $l_{y}$. In an economy where loan supply is more reactive than loan demand to the fluctuations in the output gap (namely, $b+\tau \delta_{y}>l_{y}$ ), an increase in the output gap leads to a reduction in the value of the interest rate $^{7}$. The second elasticity $\theta_{r}$ relies to the diffusion of monetary policy decisions to stabilize the economy. The value of this parameter depends on a ratio between the interest rate elasticity of loan supply $\left(\tau \delta_{r}\right)$ and the elasticity of loan demand $\left(l_{\rho}\right)$. The imperfect transmission of monetary policy decisions on the loan interest rate constitutes a second financial friction in the economy, as it creates some uncertainty on the final impact of central bank decisions on the macroeconomic equilibrium. When loan demand is more reactive than loan supply to the fluctuations of the central bank policy rate, commercial banks may increase their margin by dampening the decrease of the interest rate.

In this paper, we concentrate on the procyclicality of financial decisions (we set $\theta_{y}>1$ ). By imposing $\tau \delta_{r}=l_{\rho}$ we assume a complete interest rate pass through (i.e., $\theta_{r}=1$ ). This restriction is useful as it leads to a simplified expression of the financial accelerator $(F A)$ as in Bernanke et al. (1999) more suited to intermediate macroeconomics. ${ }^{8}$

The introduction of macroprudential measures affects the structure of the FA relation. We follow Cecchetti \& Kohler (2012), by assuming that the instrument set by the relevant authorities is related to bank capital requirements $(k)$. As previously underlined, the main problem stems from the procyclicality of financial decisions. This macroprudential instrument moderates the financial cycle, as it constrains the increase of loans in good times, while it dampens the reduction of loans in bad times. The aggregate supply of loans now writes ${ }^{9}$,

$$
L^{S}=B-\varkappa k+\tau D
$$

where parameter $\varkappa$ measures the sensitivity of loans supplied by the consolidated banking 
system to capital requirements $k$. Solving the equilibrium condition of the loan market $\left(L^{D}=L^{S}\right)$ for the value of the lending rate $\rho$, with a complete interest rate pass-through, this new instrument affects the financial accelerator $\left(F A^{\prime}\right)$ as it drives a wedge between the interest rate spread $(\rho-r)$ and the output gap $(y)$,

$$
F A^{\prime}: \rho-r=-\theta_{y} y+\theta_{k} k
$$

In this expression, $\theta_{k}=\varkappa / l_{\rho}$ is the elasticity of the interest rate gap to the bank capital requirement: it is equal to the ratio between the sensitivity of the loan supply to this instrument and the elasticity of loan demand to the lending interest rate. In this situation, the authorities in charge of financial stability can control the interest rate spread with their own policy instrument, $k$. As a consequence, the interest rate $r$ can be used conventionally by the central bank to stabilize prices in the economy. As an example, if the banking system issues too much loans with respect to the macroeconomic performance of the economy, a rise in the value of $k$, by increasing the interest rate paid on loans, may reduce the incentives to borrow. It thus reduces the incentive for risk taking and builds up buffers ex-ante to avoid a financial crisis. 


\section{NOTES}

${ }^{1}$ This paper should thus be considered as a possible complement to Walsh (2002) (that presents the main features of inflation targeting in a pre-crisis environment), Bofinger et al. (2006) (that present both a compact way of introducing the 3-equation New Keynesian Model and that introduce the students to the debate between simple and optimal monetary rules), Friedman (2013) (that discusses the way unconventional monetary policy measures should be conducted in a New Keynesian Model following the financial crisis), Buttet \& Roy (2014) (that offer a simple treatment of the question of conduct of monetary policy at the zero lower bound ) and Woodford (2010) (that presents the way financial intermediation should be integrated into macroeconomic analysis and how it should be taken into account for the conduct of monetary policy).

${ }^{2}$ The microfoundation of this relation is provided in appendix section A.

${ }^{3}$ The solution procedure is as follows: combining the targeting rule with the Phillips curve we get a solution for either the output gap or the inflation gap; combining the solution for the output gap with the loan market equilibrium condition, we get the interest rate gap.

${ }^{4}$ An extensive presentation of this situation is proposed by Bofinger et al. (2006).

${ }^{5}$ See appendix section A.

${ }^{6}$ As suggested by Gelain and Ilbas (2014), the output gap in the macroprudential authorities' loss function reflects the concern to stabilize the indirect effects coming from financial imbalances that are not included in the monetary authority's loss function, but could affect the real economy even in the presence of price stability. This modeling choice is useful to account for the Basel III regulation that refers to "reducing the risk of spillover from the financial sector to the real economy" as one of the main objectives of the regulatory reforms. Furthermore, Angelini et al. (2011) adopt a similar approach to address financial disruption in order to avoid negative real economy effects.

${ }^{7}$ This phenomenon can be traced to the various distortions inherent in financial relationships stemming from the existence of asymmetric information between banks and borrowers. In this setting an increase in the output gap improves the collateral of borrower and lead banks to decrease lending rate. By so intermediaries may give rise to excessive risk-taking: there can be an endogenous build-up of imbalances within the financial system that, in the case of an adverse event, could generate a systemic event.

${ }^{8}$ In this simplified setting, keeping a unitary interest rate pass-through leads to the divine coincidence as presented by Bofinger et al. (2006). This situation simplifies the computation of the results in this model. An imperfect interest rate pass-through would affect the transmission of monetary policy decisions on the economy. By so, it will have consequences under an optimal monetary policy as it suppresses the divine coincidence and reintroduces the impact of demand shocks on activity and on inflation. Although this 
question matters in real life situations, it is only secondary for the question at hand in this paper.

${ }^{9}$ In this simplified framework, the main difference between the capital requirement instrument and the rate of reserves of banks is that the first instrument accounts for the whole range of bank assets while the second one is set on private sector deposits. 


\section{References}

Bernanke, B. S., \& Blinder, A. S. (1989). Credit, money, and aggregate demand. National Bureau of Economic Research Cambridge, Mass., USA.

Bernanke, B. S., Gertler, M., \& Gilchrist, S. (1999). The financial accelerator in a quantitative business cycle framework. Handbook of Macroeconomics, 1, 1341-1393.

Bofinger, P., Mayer, E., \& Wollmershäuser, T. (2006). The bmw model: a new framework for teaching monetary economics. The Journal of Economic Education, 37(1), 98-117.

Buttet, S., \& Roy, U. (2014). A simple treatment of the liquidity trap for intermediate macroeconomics courses. The Journal of Economic Education, 45(1), 36-55.

Cecchetti, S. G., \& Kohler, M. (2012). When capital adequacy and interest rate policy are substitutes (and when they are not). Bank for International Settlements, Working Paper, 379.

Cecchetti, S. G., \& Li, L. (2008). Do capital adequacy requirements matter for monetary policy? Economic Inquiry, 46(4), 643-659.

De Paoli, B., \& Paustian, M. (2013). Coordinating monetary and macroprudential policies. Federal Reserve Bank of New York, Staff Report, 653.

Friedman, B. M. (2013). The simple analytics of monetary policy: A post-crisis approach. The Journal of Economic Education, 44(4), 311-328.

Galati, G., \& Moessner, R. (2013). Macroprudential policy-a literature review. Journal of Economic Surveys, 27(5), 846-878.

Tinbergen, J. (1952). On the theory of economic policy.

Walsh, C. E. (2002). Teaching inflation targeting: An analysis for intermediate macro. The Journal of Economic Education, 33(4), 333-346.

Woodford, M. (2010). Financial intermediation and macroeconomic analysis. The Journal of Economic Perspectives, 21-44. 


\begin{tabular}{clll}
\hline \multicolumn{3}{c}{ With financial frictions $\left(\theta_{y}>0\right)$} & Without financial frictions $\left(\theta_{y}=0\right)$ \\
\hline$\partial y^{*} / \partial \epsilon_{D}$ & $\left|\frac{1}{\left(1-\alpha_{\rho} \theta_{y}\right)+\left(\alpha_{r}+\alpha_{\rho}\right)\left(\beta_{y}+\beta_{\pi} \sigma_{y}\right)}\right|$ & $\left|\frac{1}{1+\left(\alpha_{r}+\alpha_{\rho}\right)\left(\beta_{y}+\beta_{\pi} \sigma_{y}\right)}\right|$ \\
$\partial y^{*} / \partial \epsilon_{S}$ & $\left|\frac{-\left(\alpha_{r}+\alpha_{\rho}\right) \beta_{\pi}}{\left(1-\alpha_{\rho} \theta_{y}\right)+\left(\alpha_{r}+\alpha_{\rho}\right)\left(\beta_{y}+\beta_{\pi} \sigma_{y}\right)}\right|$ & $>$ & $\left|\frac{-\left(\alpha_{r}+\alpha_{\rho}\right) \beta_{\pi}}{1+\left(\alpha_{r}+\alpha_{\rho}\right)\left(\beta_{y}+\beta_{\pi} \sigma_{y}\right)}\right|$ \\
$\partial \pi^{*} / \partial \epsilon_{D}$ & $\left|\frac{\sigma_{y}}{\left(1-\alpha_{\rho} \theta_{y}\right)+\left(\alpha_{r}+\alpha_{\rho}\right)\left(\beta_{y}+\beta_{\pi} \sigma_{y}\right)}\right|$ & $>$ & $\left|\frac{\sigma_{y}}{1+\left(\alpha_{r}+\alpha_{\rho}\right)\left(\beta_{y}+\beta_{\pi} \sigma_{y}\right)}\right|$ \\
$\partial \pi^{*} / \partial \epsilon_{S}$ & $\left|\frac{\left(1-\alpha_{\rho} \theta_{y}\right)+\left(\alpha_{r}+\alpha_{\rho}\right) \beta_{y}}{\left(1-\alpha_{\rho} \theta_{y}\right)+\left(\alpha_{r}+\alpha_{\rho}\right)\left(\beta_{y}+\beta_{\pi} \sigma_{y}\right)}\right|$ & $<$ & $\left|\frac{1+\alpha_{r} \beta_{y}}{1+\left(\alpha_{r}+\alpha_{\rho}\right)\left(\beta_{y}+\beta_{\pi} \sigma_{y}\right)}\right|$ \\
\hline
\end{tabular}

TABLE 1: Diffusion of supply and demand shocks with and without financial frictions.

\begin{tabular}{cccc}
\hline & Standard Policy & $\begin{array}{c}\text { Extended Policy } \\
\text { with Financial Stability }\end{array}$ & Cooperative Equilibrium \\
\hline$\left(\pi-\pi_{0}\right)$ & $\frac{1}{1+\sigma_{y}^{2} \gamma_{1}} \epsilon_{S}$ & $\frac{1+\theta_{y}^{2} \gamma_{2}}{1+\theta_{y}^{2} \gamma_{2}+\sigma_{y}^{2} \gamma_{1}} \epsilon_{S}$ & $\frac{2}{\left(2+\sigma_{y}^{2} \gamma_{1}\right)} \epsilon_{S}$ \\
$y$ & $-\frac{\sigma_{y} \gamma_{1}}{1+\sigma_{y}^{2} \gamma_{1}} \epsilon_{S}$ & $\frac{\sigma_{y} \gamma_{1}}{1+\theta_{y}^{2} \gamma_{2}+\sigma_{y}^{2} \gamma_{1}} \epsilon_{S}$ & $-\frac{\sigma_{y} \gamma_{1}}{\left(2+\sigma_{y}^{2} \gamma_{1}\right)} \epsilon_{S}$ \\
$(\rho-r)$ & $\frac{\theta_{y} \sigma_{y} \gamma_{1}}{1+\sigma_{y}^{2} \gamma_{1}} \epsilon_{S}$ & $\frac{\sigma_{y} \theta_{y}^{2} \gamma_{2}}{1+\theta_{y}^{2} \gamma_{2}+\sigma_{y}^{2} \gamma_{1}} \epsilon_{S}$ & 0 \\
\hline
\end{tabular}

TABLE 2: the three gaps under optimal policy. 


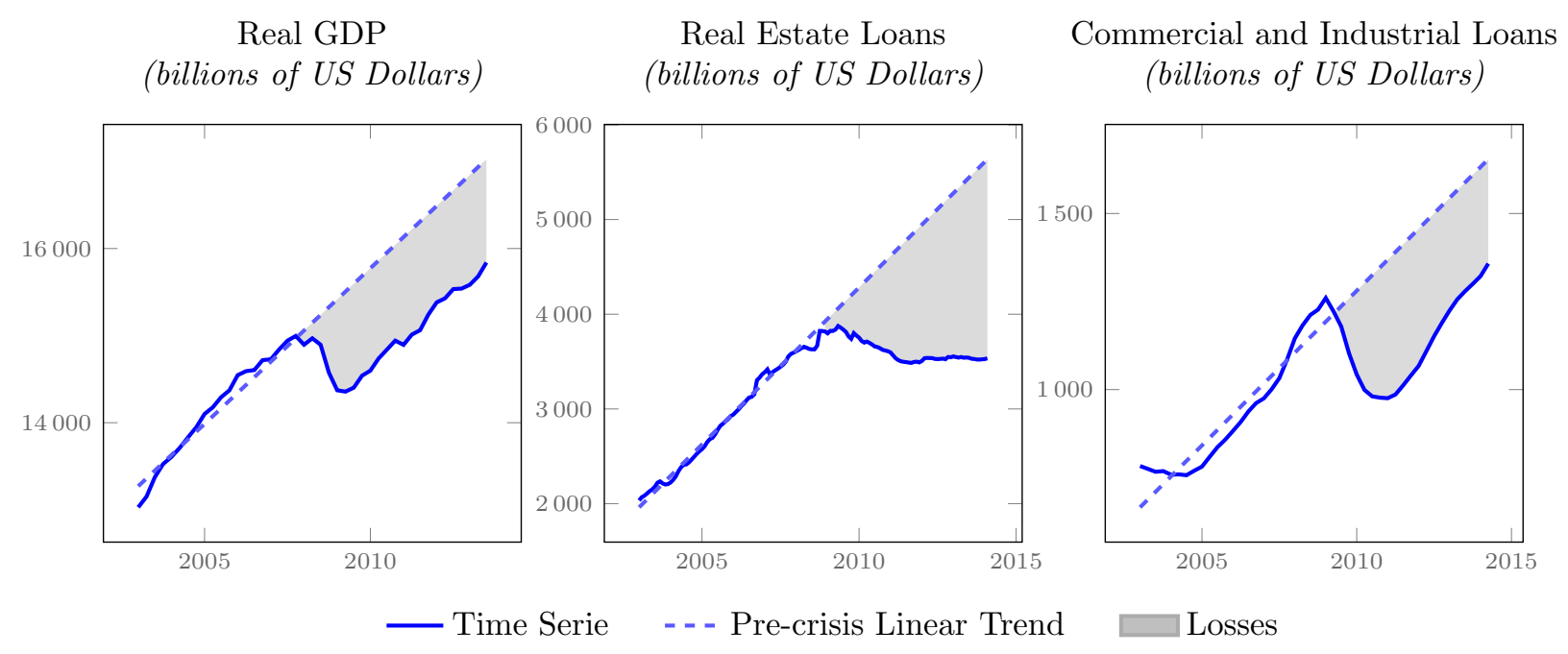

FIGURE 1: Output and loan costs after the 2007 financial crisis episode for the US economy.

Sources: FRED database.

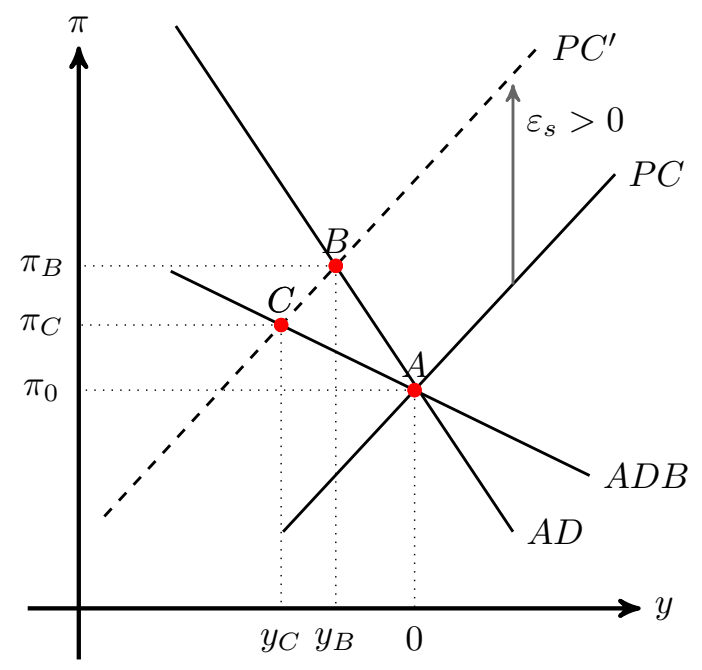

(a) Positive cost push shock $\epsilon_{S}>0$

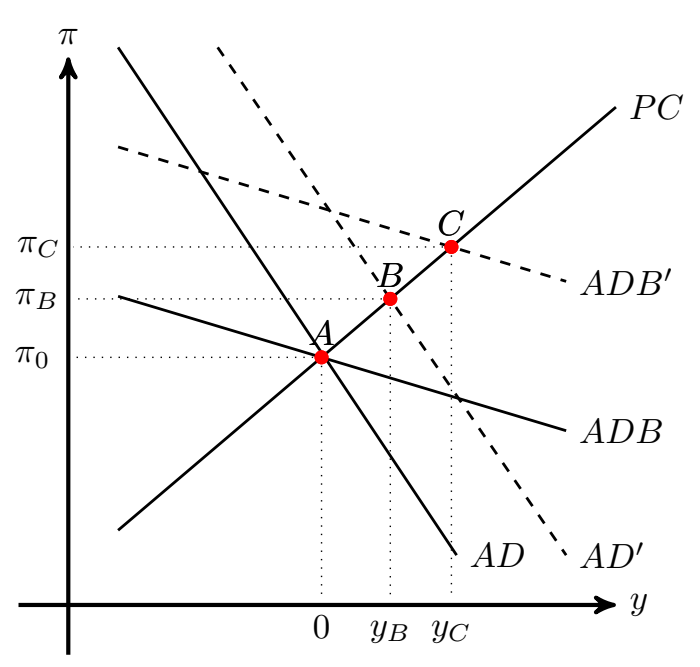

(b) Positive demand shock $\epsilon_{D}>0$

FIGURE 2: A comparison of supply and demand shocks effects with and without financial frictions 